\title{
Generation and observation of fast deuterium ions and fusion-born alpha particles in JET D-3He plasmas with the 3-ion radio-frequency heating scenario
}

Nocente, Massimo; Kazakov, Yevgen; Garcia, J.; Kiptily, Vasily; Ongena, Jozef; Dreval, Mykola; Fitzgerald, Michael; Sharapov, Sergei E; Štancar, Žiga; Weisen, Henri

Total number of authors:

46

Published in:

Nuclear Fusion

Link to article, DOI:

$10.1088 / 1741-4326 / a b b 95 d$

Publication date:

2020

Document Version

Peer reviewed version

Link back to DTU Orbit

Citation (APA):

Nocente, M., Kazakov, Y., Garcia, J., Kiptily, V., Ongena, J., Dreval, M., Fitzgerald, M., Sharapov, S. E., Štancar, Ž., Weisen, H., Baranov, Y., Bierwage, A., Craciunescu, T., Dal Molin, A., de la Luna, E., Dumont, R., Dumortier, P., Eriksson, J., Giacomelli, L., ... Zghar, A. (2020). Generation and observation of fast deuterium ions and fusion-born alpha particles in JET D- He plasmas with the 3-ion radio-frequency heating scenario. Nuclear Fusion, 60(12), [124006]. https://doi.org/10.1088/1741-4326/abb95d

\section{General rights}

Copyright and moral rights for the publications made accessible in the public portal are retained by the authors and/or other copyright owners and it is a condition of accessing publications that users recognise and abide by the legal requirements associated with these rights.

- Users may download and print one copy of any publication from the public portal for the purpose of private study or research.

- You may not further distribute the material or use it for any profit-making activity or commercial gain

- You may freely distribute the URL identifying the publication in the public portal 


\section{Generation and observation of fast deuterium ions and fusion-born alpha particles in JET D- ${ }^{3} \mathrm{He}$ plasmas with the 3-ion radio-frequency heating scenario}

To cite this article before publication: Massimo Nocente et al 2020 Nucl. Fusion in press https://doi.org/10.1088/1741-4326/abb95d

\section{Manuscript version: Accepted Manuscript}

Accepted Manuscript is "the version of the article accepted for publication including all changes made as a result of the peer review process, and which may also include the addition to the article by IOP Publishing of a header, an article ID, a cover sheet and/or an 'Accepted Manuscript' watermark, but excluding any other editing, typesetting or other changes made by IOP Publishing and/or its licensors"

This Accepted Manuscript is $\odot 2020$ The Author(s). Published by IOP Publishing Ltd..

During the embargo period (the 12 month period from the publication of the Version of Record of this article), the Accepted Manuscript is fully protected by copyright and cannot be reused or reposted elsewhere.

As the Version of Record of this article is going to be / has been published on a subscription basis, this Accepted Manuscript is available for reuse under a CC BY-NC-ND 3.0 licence after the 12 month embargo period.

After the embargo period, everyone is permitted to use copy and redistribute this article for non-commercial purposes only, provided that they adhere to all the terms of the licence https://creativecommons.org/licences/by-nc-nd/3.0

Although reasonable endeavours have been taken to obtain all necessary permissions from third parties to include their copyrighted content within this article, their full citation and copyright line may not be present in this Accepted Manuscript version. Before using any content from this article, please refer to the Version of Record on IOPscience once published for full citation and copyright details, as permissions will likely be required. All third party content is fully copyright protected, unless specifically stated otherwise in the figure caption in the Version of Record.

View the article online for updates and enhancements. 
M. Nocente ${ }^{1,2}$, Y. Kazakov ${ }^{3}$, J. Garcia ${ }^{4}$, V.G. Kiptily ${ }^{5}$, J.

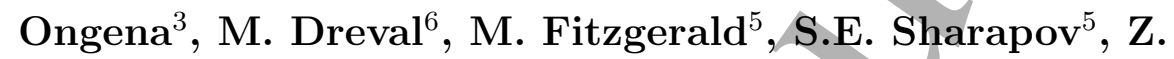

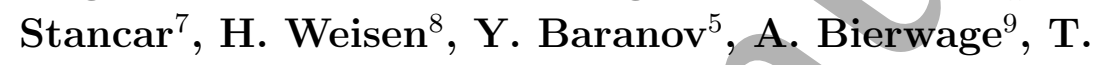
Craciunescu $^{10}$, A. Dal Molin ${ }^{1}$, E. de la Luna ${ }^{11}$, R. Dumont ${ }^{4}$, P. Dumortier $^{3}$, J. Eriksson ${ }^{12}$, L. Giacomelli ${ }^{2}$, C. Giroud ${ }^{5}$, V. Goloborodko $^{13}$, G. Gorini ${ }^{1,2}$, E. Khilkevitch ${ }^{14}$, K.K. Kirov ${ }^{5}$, M. Iliasova $^{14}$, P. Jacquet ${ }^{3}$, P. Lauber ${ }^{15}$, E. Lerche ${ }^{3}$, M.J. Mantsinen $^{16}$, A. Mariani ${ }^{2}$, S. Mazzi ${ }^{17,4}$, F. Nabais ${ }^{18}$, M.F.F. Nave $^{18}$, J. Oliver ${ }^{5}$, E. Panontin ${ }^{1}$, D. Rigamonti ${ }^{2}$, A. Sahlberg ${ }^{12}$, M. Salewski ${ }^{19}$, A. Shevelev ${ }^{14}$, K. Shinohara ${ }^{20}$, P. Siren ${ }^{21}$, S. Sumida $^{22}$, M. Tardocchi ${ }^{2}$, D. Van Eester ${ }^{3}$, J. Varje ${ }^{21}$, A. Zohar ${ }^{7}$ and JET Contributors $\ddagger$

E-mail: massimo.nocente@mib.infn.it

${ }^{1}$ Dipartimento di Física "G. Occhialini", Università di Milano-Bicocca, Milano, Italy

${ }^{2}$ Institute for Plasma Science and Technology, National Research Council, Milan, Italy

${ }^{3}$ Laboratory for Plasma Physics, LPP-ERM/KMS Partner in the Trilateral Euregio Cluster (TEC), Brussels, Belgium

${ }^{4}$ CEA, IRFM, 13108, Saint-Paul-lez-Durance, France

${ }^{5}$ CCFE, Culham Science Centre, Abingdon, UK

${ }^{6}$ National Science Centre, Kharkiv, Ukraine

7 Jozef Stefan Institute, Ljubljana, Slovenia

8 EPFL, Swiss Plasma Center, Lausanne, Switzerland

${ }^{9}$ QST Rokkashø Fusion Institute, Rokkasho, Japan

10 National Institute for Laser, Plasma and Radiation Physics, Bucharest, Romania

${ }^{11}$ Laboratorio Nacional de Fusión, CIEMAT, E-28040 Madrid, Spain

12 Department of Physics and Astronomy, Uppsala University, Uppsala, Sweden

13 Institute for Nuclear Research, Kyiv, Ukraine

14 Ioffe Institute, St. Petersburg, Russia

${ }^{15}$ Max-Planck Institute for Plasma Physics, Garching, Germany

${ }^{16}$ Barcelona Supercomputing Center and ICREA, Barcelona, Spain

17 Aix-Marseille Université, CNRS PIIM, UMR 7345 Marseille, France

18 IST, Universidade de Lisboa, Lisbon, Portugal

19 Department of Physics, Technical University of Denmark, Kgs. Lyngby, Denmark

See the author list of E. Joffrin et al. 2019 Nucl. Fusion 59112021 
Fast ion generation with the $\mathrm{D}-{ }^{3} \mathrm{He}$ 3-ion scenario

20 The University of Tokyo, Kashiwa 277-8561, Japan

${ }^{21}$ Aalto University, Aalto, Finland

${ }^{22}$ QST Naka Fusion Institute, Ibaraki, Japan

9 September 2020

\begin{abstract}
.
Dedicated experiments to generate energetic D ions and D - ${ }^{3}$ He fusion-born alpha particles were performed at the Joint European Torus (JET) with the ITER-like wall (ILW). Using the 3-ion D - $\left(\mathrm{D}_{\mathrm{NBI}}\right)-{ }^{3} \mathrm{He}$ radio frequency (RF) heating scenario, deuterium ions from neutral beam injection (NBI) were accelerated in the core of mixed $\mathrm{D}-{ }^{3} \mathrm{He}$ plasmas to higher energies with ion cyclotron resonance frequency (ICRF) waves, in turn leading to a core-localized source of alpha particles. The fastion distribution of RF-accelerated D-NBI ions was controlled by varying the ICRF and NBI power $\left(\mathrm{P}_{\mathrm{ICRF}} \approx 4-6 \mathrm{MW}, \mathrm{P}_{\mathrm{NBI}} \approx 3-20 \mathrm{MW}\right)$, resulting in rather high $\mathrm{D}-\mathrm{D}$ neutron $\left(\approx 1 \times 10^{16} \mathrm{~s}^{-1}\right)$ and $\mathrm{D}-{ }^{3} \mathrm{He}$ alpha rates $\left(\approx 2 \times 10^{16} \mathrm{~s}^{-1}\right)$ at moderate input heating power. Theory and TRANSP analysis show that large populations of co passing MeVrange $\mathrm{D}$ ions were generated using the $\mathrm{D}-\left(\mathrm{D}_{\mathrm{NBI}}\right)-{ }^{3} \mathrm{He} 3$-ion ICRF scenario. This important result is corroborated by several experimental observations, in particular gamma-ray measurements. The/developed experimental scenario at JET provides unique conditions for probing several aspects of future burning plasmas, such as the contribution from $\mathrm{MeV}$ range ions to global confinement, but without introducing tritium. Dominant fast-ion core electron heating with $T_{i} \approx T_{e}$ and a rich variety of fast-ion driven Alfvén eigenmodes (AEs) were observed in these $\mathrm{D}-{ }^{3}$ He plasmas. The observed AE activities do not have a detrimental effect on the thermal confinement and, in some cases, may be driven by the fusion born alpha particles. A strong continuous increase in neutron rate was observed during long-period sawteeth $(>1$ s), accompanied by the observation of reversed shear AEs, which implies that a non monotonic q profile was systematically developed in these plasmas, sustained by the large fast-ion populations generated by the 3 -ion ICRF scenario.
\end{abstract}

Keywords: Fast ion generation, radio-frequency heating, 3-ion scenario, D $-{ }^{3}$ He plasmas, $\mathrm{MeV}$ range ions

\title{
1. Introduction
}

Understanding the transport and confinement of fast ions and, in particular, fusion born alpha particles in burning plasmas is one of the key missions to demonstrate the feasibility of fusion as an energy source. Although a number of aspects of alpha particle physics can only be studied in burning plasmas, some can be anticipated in present machines. To this end, the Joint European Torus (JET) has established an ambitious scientific program in preparation of its future deuterium-tritium (DTE2) campaign, aiming, among others, at developing dedicated scenarios where the effects of alpha particles from the fusion reactions can be studied $[1,2]$.

One possibility is offered by the 3 -ion radio-frequency ( $\mathrm{RF}$ ) heating scenario [3, 4] in D-T plasmas, by accelerating tritons or deuterons from neutral beam injection (NBI) to 
high enough energies that maximize the D-T reactivity [5] at moderate input auxiliary heating power. This fast-ion scenario relies on the combined use of NBI and ICRF where NBI provides the source of resonant absorbers at the ion-ion hybrid (IIH) layer in mixed plasmas, where the left-hand RF polarization is strongly enhanced. The fast-ion distribution function of the RF-accelerated beam ions can be controlled by varying the ratio $\mathrm{P}_{\mathrm{ICRF}} / \mathrm{P}_{\mathrm{NBI}}$. In this way rather high neutron rates can be obtained with a moderate amount of total auxiliary heating power, as shown in proof-of-principle studies in H-D plasmas on JET $[5,6]$. In view of demonstrating the feasibility of this heating scenario for alpha physics studies in $\mathrm{D}-\mathrm{T}$, we have performed a series of dedicated experiments in mixed $\mathrm{D}-{ }^{3} \mathrm{He}$ plasmas on $\operatorname{JET}\left(\mathrm{B}_{0} \approx 3.7 \mathrm{~T}, \mathrm{I}_{\mathrm{p}}=2.5 \mathrm{MA}, \mathrm{n}_{\mathrm{e} 0} \approx 6 \times 10^{19} \mathrm{~m}^{-3}\right.$, $\mathrm{f}=$ 32.2-33.0 MHz, dipole phasing; $\mathrm{B}_{0}, \mathrm{I}_{\mathrm{p}}, \mathrm{n}_{\mathrm{e} 0}$ and $\mathrm{f}$ are here the core magnetic field, plasma current, core electron density and applied $\mathrm{RF}$ frequency, respectively). In these studies, large ${ }^{3} \mathrm{He}$ concentrations $\mathrm{n}\left({ }^{3} \mathrm{He}\right) / \mathrm{n}_{\mathrm{e}} \approx 20-25 \%$ were used to purposely position the IIH layer in the plasma core, where acceleration of D-NBI ions with ICRF waves was expected to take place (see figure 1 ). Note the dual function for ${ }^{3} \mathrm{He}$ ions in this fast-ion scenario. The concentration of ${ }^{3} \mathrm{He}$ ions not only defines the location of the IIH layer (similar to the effect of the isotopic H:D ratio in earlier experiments with the 3-ion D-( $\left.\mathrm{D}_{\mathrm{NBI}}\right)$-H scenario [5]), but the ${ }^{3} \mathrm{He}$ ions also act as the target in $\mathrm{D}-{ }^{3} \mathrm{He}$ fusion reactions [7] with deuterons accelerated by ICRF:

$$
\mathrm{D} \text { (fast) }+{ }^{3} \mathrm{He} \text { (target) } \rightarrow{ }^{4} \mathrm{He}(3.6 \mathrm{MeV})+\mathrm{p}(14.7 \mathrm{MeV})
$$

With the IIH layer placed on-axis, the cyclotron resonances for thermal D and ${ }^{3} \mathrm{He}$ ions are located at the high field side and low field side off-axis, as shown in Fig. 1. Note that neither thermal D nor ${ }^{3} \mathrm{He}$ ions can fulfil the resonance condition for the fundamental ion cyclotron interaction, $\omega=\omega_{c i}+k_{\|} v_{\|, i}$, at the IIH layer, where most of the power absorption takes place thanks to the left handed polarization of the RF wave electric field in this region. Here, $k_{\|}$and $v_{\|}$are the wavenumber and particle velocity parallel to the confining magnetic field. Similar to earlier experiments in mixed H-D plasmas, tangential NBI injectors with $\mathrm{E}_{\mathrm{NBI}} \approx 100 \mathrm{keV}$ and pitch $\lambda=v_{\|} / v \approx 0.62$ were used to provide resonant absorbers at the position of the IIH layer. Guided by former experiments with the 3 -ion D - $\left(\mathrm{D}_{\mathrm{NBI}}\right)-\mathrm{H}$ scenario and associated PION analysis [5, 8], we varied the ICRF and NBI power $\left(\mathrm{P}_{\mathrm{ICRF}} \approx 4-6 \mathrm{MW}, \mathrm{P}_{\mathrm{NBI}} \approx 3-20 \mathrm{MW}\right)$ and the ratio $\mathrm{P}_{\mathrm{ICRF}} / \mathrm{P}_{\mathrm{NBI}}$, as main actuators to change the fast-ion distribution of RF-accelerated $\mathrm{D}$ NBI ions. This resulted in D-D neutron rates that ranged between $\approx 2 \times 10^{15} \mathrm{~s}^{-1}$ and $\approx 1 \times 10^{16} \mathrm{~s}^{-1}$ in the series of discharges we have performed, at variable $\mathrm{P}_{\mathrm{ICRF}} / \mathrm{P}_{\mathrm{NBI}}$. The extended set of JET fast-ion measurements, in particular neutron [9] and gammaray spectrometers $[10,11]$, have been used to provide information on the energy and spatial distribution of the accelerated deuterium and fusion-born alpha particles $[12,13]$. Recent upgrades of the gamma-ray diagnostic at JET $[14,15,16,17]$ made it possible to unambiguously identify the production of $\mathrm{MeV}$-range deuterons and fusion-born alpha particles and to study some of their properties.

In this paper we describe the main experimental results obtained in recent fast-ion 
Fast ion generation with the $\mathrm{D}-{ }^{3} \mathrm{He}$ 3-ion scenario

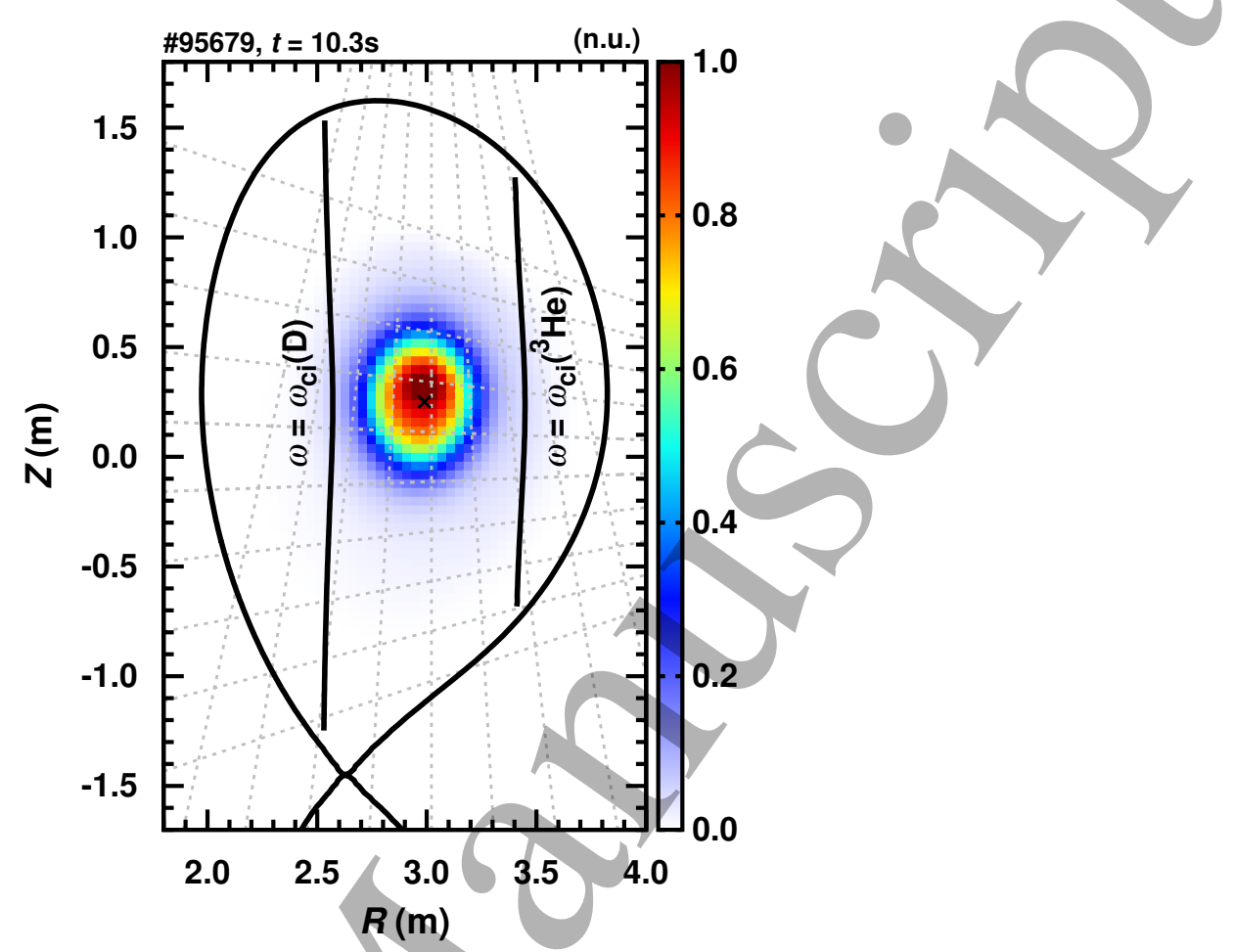

Figure 1. The poloidal cross-section of the JET tokamak with off-axis location of the ion cyclotron resonance for thermal $\mathrm{D}$ and ${ }^{3} \mathrm{He}$ ions for 3 -ion ICRF fast-ion experiments in $\mathrm{D}-{ }^{3}$ He plasmas $\left(3.7 \mathrm{~T} / 2.5 \mathrm{MA}, \mathrm{n}_{\mathrm{e} 0} \approx 6 \times 10^{19} \mathrm{~m}^{-3}, \mathrm{f}=32.2-33.0 \mathrm{MHz}\right.$, dipole phasing, $\left.\mathrm{E}_{\mathrm{NBI}} \approx 100 \mathrm{keV}\right)$. The coloured image is a tomographic reconstruction of the neutron emissivity for discharge \#95679. The dashed lines are the lines of sight of the JET neutron camera [18].

experiments on JET with the 3-ion D-( $\left.\mathrm{D}_{\mathrm{NBI}}\right)-{ }^{3} \mathrm{He}$ scenario, including the unambiguous confirmation of the generation of co-passing energetic D ions and fusion-born alpha particles in the plasma core. These plasmas show a number of additional, interesting phenomena linked to the presence of the energetic ions generated by the 3-ion scenario. In particular, the rich variety of fast-ion driven Alfvén eigenmodes (AEs) observed raise a number of questions that deserve detailed further investigations. Rather surprisingly, the complex AE activity seems not to be detrimental for the thermal confinement as indicated, among others, by the systematic observation of $T_{i} \approx T_{e}$ in these plasmas with dominant core electron heating from the fast ions. Another important observation is the systematic appearance of reversed shear AEs (RSAEs) during monster sawteeth $(>\approx$ $1 \mathrm{~s})$, indicating that a non monotonic q-profile was developed and sustained in these plasmas by the large fast-ion populations generated by the 3-ion ICRF scenario.

\section{Experimental results}

Figure 2 shows the time evolution of the main physical parameters of two JET-ILW pulses \#94698 and \#95679, where the $\mathrm{D}-\left(\mathrm{D}_{\mathrm{NBI}}\right)-{ }^{3}$ He 3-ion scenario was applied to 
Fast ion generation with the $\mathrm{D}-{ }^{3}$ He 3 -ion scenario
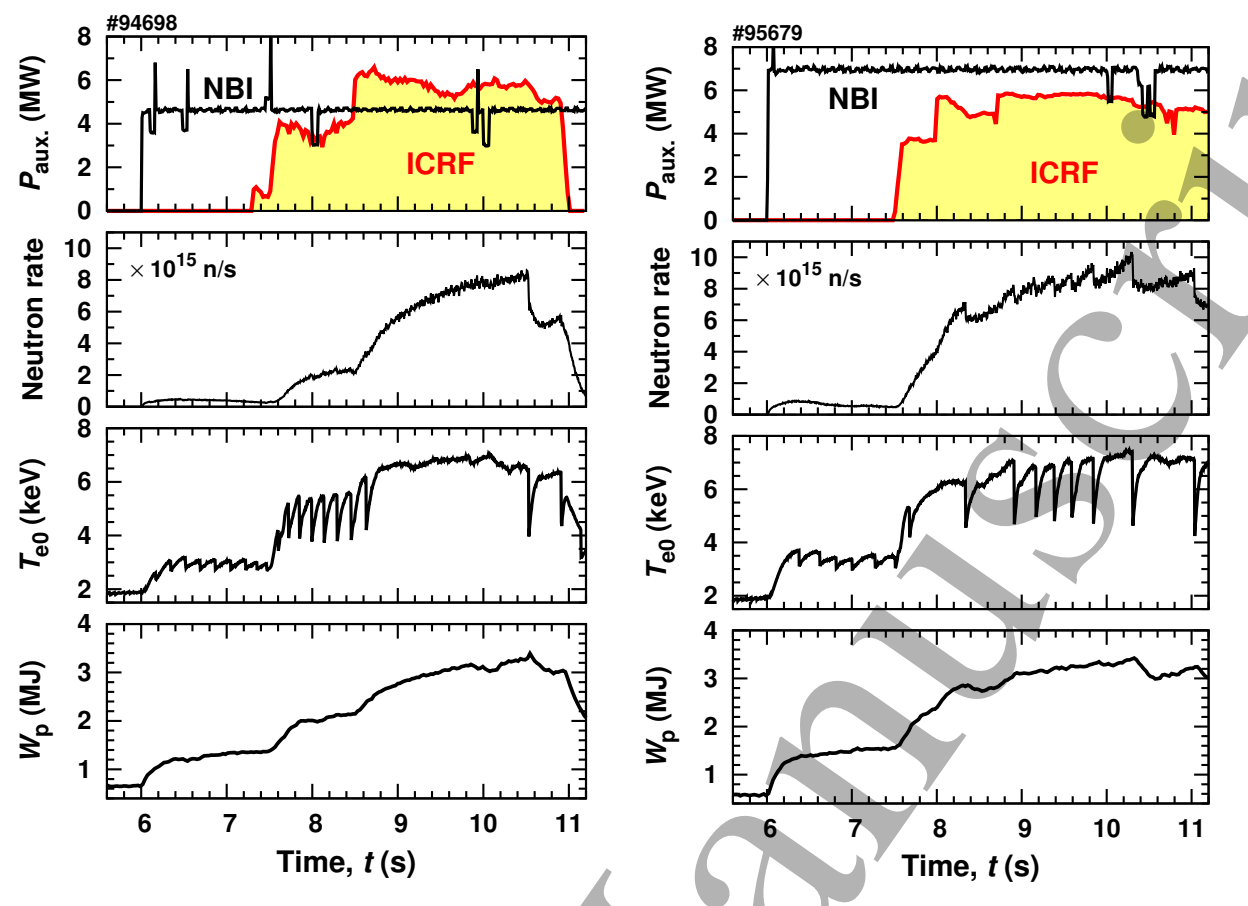

Figure 2. Overview of two JET-ILW pulses in mixed $\mathrm{D}-{ }^{3} \mathrm{He}$ plasmas, where the 3-ion $\mathrm{D}-\left(\mathrm{D}_{\mathrm{NBI}}\right)-{ }^{3} \mathrm{He}$ scenario was applied $\left(3.7 \mathrm{~T} / 2.5 \mathrm{MA}, \mathrm{n}_{\mathrm{e} 0} \approx 6 \times 10^{19} \mathrm{~m}^{-3}\right.$, $n^{3}{ }_{\mathrm{He}} / n_{e} \approx 20-25 \%$ ): (a) \#94698 and (b) \#95679. The panels from top to bottom show the NBI and ICRF power, neutron rate, the central electron temperature and the plasma stored energy.

generate high-energy $\mathrm{D}$ ions in the core of the $\mathrm{D}-{ }^{3}$ He plasma. In these experiments, a high central toroidal magnetic field of $3.7 \mathrm{~T}$ was applied and plasmas stayed in L-mode $\left(3.7 \mathrm{~T} / 2.5 \mathrm{MA}, \mathrm{n}_{\mathrm{e} 0} \approx 6 \times 10^{19} \mathrm{~m}^{-3}, \mathrm{n}\left({ }^{3} \mathrm{He}\right) / \mathrm{n}_{\mathrm{e}} \approx 20-25 \%\right)$. Pulses \#94698 and \#95679 had a comparable maximum ICRF power $(\approx 5.5-6.0 \mathrm{MW})$, but different NBI power of $\approx 4.6 \mathrm{MW}$ and $\approx 7.0 \mathrm{MW}$. The efficient generation of high-energy D ions with ICRF can be immediately seen by comparing the time traces for the measured neutron rate and central electron temperature in the phases with NBI-only and the combined NBI+ICRF phases. Note the larger ratio $\mathrm{P}_{\mathrm{ICRF}} / \mathrm{P}_{\mathrm{NBI}} \approx 1.3$ in JET pulse \#94698 as compared to $\mathrm{P}_{\mathrm{ICRF}} / \mathrm{P}_{\mathrm{NBI}} \approx 0.8$ in $\# 95679$, resulting in quite different sawtooth dynamics in these two pulses. In pulse \#94698, a monster sawtooth with $\Delta t_{s w} \approx 1.9 \mathrm{~s}(\mathrm{t}=8.63-10.53 \mathrm{~s})$ was observed in the phase with $\mathrm{P}_{\mathrm{ICRF}} \approx 5.8 \mathrm{MW}$. In pulse \#95679 with higher NBI power and lower $\mathrm{P}_{\mathrm{ICRF}} / \mathrm{P}_{\mathrm{NBI}}$, the period of sawtooth oscillations was significantly shorter, varying between $\approx 200-300 \mathrm{~ms}$ and $\approx 700 \mathrm{~ms}$.

There is a remarkable increase in the neutron rate when ICRF is applied in combination with NBI. In pulse \#94698, the neutron rate increased from $\approx 3 \times 10^{14}$ $\mathrm{s}^{-1}$ in the NBI only phase to $\approx 2.3 \times 10^{15} \mathrm{~s}^{-1}$ in the first ICRF + NBI phase with $\approx 4.0 \mathrm{MW}$ of $\mathrm{ICRF}$, and later to $\approx 8.2 \times 10^{15} \mathrm{~s}^{-1}$ when the $\mathrm{ICRF}$ power reached $\approx 6.0$ MW. Note the continuous increase in neutron rate and plasma stored energy during the monster sawtooth phase in \#94698. In pulse \#95679, an even higher neutron rate of 


\section{Fast ion generation with the $\mathrm{D}-{ }^{3} \mathrm{He}$ 3-ion scenario}

$\approx 1 \times 10^{16}$ was achieved. The high efficiency of the generation of energetic $\mathrm{D}$ ions in the plasma core has been confirmed by measurements of the neutron spectrum with the TOFOR instrument [19], which has a vertical line-of-sight passing through the plasma core. TOFOR measurements for \#95679 imply that most of the deuterons had MeV range energies, up to about $\approx 2 \mathrm{MeV}$. The production of energetic $\mathrm{D}$ ions occurs together with the generation of fusion-born alpha particles from the $\mathrm{D}-{ }^{3}$ He reaction. This is demonstrated in Figure 3, showing the gamma-ray spectra recorded during the combined ICRF + NBI phase in \#95679 by two independent gamma-ray spectrometers. One is a high-purity Germanium detector [20], that has the same vertical line-of-sight passing through the plasma core as TOFOR (Fig. 3 (a)), while the other is a $\operatorname{LaBr}_{3}(\mathrm{Ce})$ detector [21], that has a tangential line of sight passing about $30 \mathrm{~cm}$ below the magnetic axis (Fig. 3 (b)). Two regions in the recorded gamma-ray spectra are important to understand the fast-ion observations and reveal more information on the fast-ion populations in these $\mathrm{D}-{ }^{3} \mathrm{He}$ plasmas. First, we note several peaks in the interval between $2 \mathrm{MeV}$ and 5 $\mathrm{MeV}$. Those in the energy range $\mathrm{E}_{\gamma}=2 \mathrm{MeV}$ to $4 \mathrm{MeV}$ originate from nuclear reactions between fast $\mathrm{D}$ ions and ${ }^{9} \mathrm{Be}$, namely $\mathrm{d}+{ }^{9} \mathrm{Be} \rightarrow \mathrm{n}+{ }^{10} \mathrm{~B}^{*}$ and $\mathrm{d}+{ }^{9} \mathrm{Be} \rightarrow \mathrm{p}+{ }^{10} \mathrm{Be}^{*}$, and that result in the production of the excited heavy nuclei ${ }^{10} \mathrm{~B}^{*}$ and ${ }^{10} \mathrm{Be}^{*}$, which decay through the emission of a gamma-ray [22]. ${ }^{9}$ Be is the main low-Z impurity in JET-ILW plasmas. The observation of these lines confirms the presence of fast $\mathrm{D}$ ions with energies of $\approx 0.5 \mathrm{MeV}$ and higher $[22,23]$, at which the cross sections for $\mathrm{D}+{ }^{9}$ Be reactions start to become significant. Of special interest is, furthemore, the peak at $\mathrm{E}_{\gamma}=4.44 \mathrm{MeV}$ and that comes from the $\alpha+{ }^{9} \mathrm{Be} \rightarrow \mathrm{n}+{ }^{12} \mathrm{C}^{*}$ reaction between ${ }^{4} \mathrm{He}$ ions in the $\mathrm{MeV}$ range and ${ }^{9} \mathrm{Be}$ impurities in the plasma. The fact that these ${ }^{4} \mathrm{He}$ ions are confined $\alpha$ particles from the $\mathrm{D}+{ }^{3} \mathrm{He}$ reaction (see/equation 1 ), and not unwanted ${ }^{4} \mathrm{He}$ impurities that may unexpectedly absorb some RF power, comes from the observation of counts in the energy range $\mathrm{E}_{\gamma}>10 \mathrm{MeV}$, see Fig. $3(\mathrm{~b})$. Note that in addition to the main channel of the $\mathrm{D}+{ }^{3} \mathrm{He}$ fusion reactions with an alpha particle as fusion product (see Eq. 1), there is a weak electromagnetic branch of this reaction, i.e. $\mathrm{d}+{ }^{3} \mathrm{He} \rightarrow \gamma+{ }^{5} \mathrm{Li}$, with ${ }^{5} \mathrm{Li}$ as the fusion product and a probability $\approx 10^{-5}$. This leads to the generation of high-energy gammas, $\mathrm{E}_{\gamma} \approx 17 \mathrm{MeV}[24,25]$. In other words, for each $10^{5} \alpha$ particles generated by $\mathrm{d}+{ }^{3} \mathrm{He} \rightarrow \alpha+\mathrm{p}$, there must be approximately one $17 \mathrm{MeV}$ gamma-ray born from the $\mathrm{d}+{ }^{3} \mathrm{He} \rightarrow \gamma \mathrm{A}^{5} \mathrm{Li}$ reaction and that we detect as the broad structure in the spectrum of figure 3 (b) because of the peculiar detection mechanism of the $17 \mathrm{MeV}$ gamma-rays, as well as due to their $\approx 1.2 \mathrm{MeV}$ intrinsic broadening at the source [26, 25]. In summary, the simultaneous observation of $\mathrm{E}_{\gamma}>10 \mathrm{MeV}$ counts in the gamma-ray spectrum of figure $3(\mathrm{~b})$, together with the $\mathrm{E}_{\gamma}=4.44 \mathrm{MeV}$ line of figure 3 (a), suggests that $\alpha$ particles are being produced by $\mathrm{d}^{3} \mathrm{He} \rightarrow \alpha+\mathrm{p}$, and are confined long enough to be detected by the gamma-ray emission from $\alpha+{ }^{9} \mathrm{Be} \rightarrow \mathrm{n}+{ }^{12} \mathrm{C}^{*}$.

Strong core localization of energetic $\mathrm{D}$ ions generated with the 3 -ion $D-\left(D_{\mathrm{NBI}}\right)-{ }^{3}$ He scenario has been independently confirmed by the measurements with the JET neutron camera [18], consisting of 10 horizontal and 9 vertical channels. Figure 1 shows the spatial profile of the neutron emission and the tomographic inversion of the 
Fast ion generation with the $\mathrm{D}-{ }^{3} \mathrm{He}$ 3-ion scenario

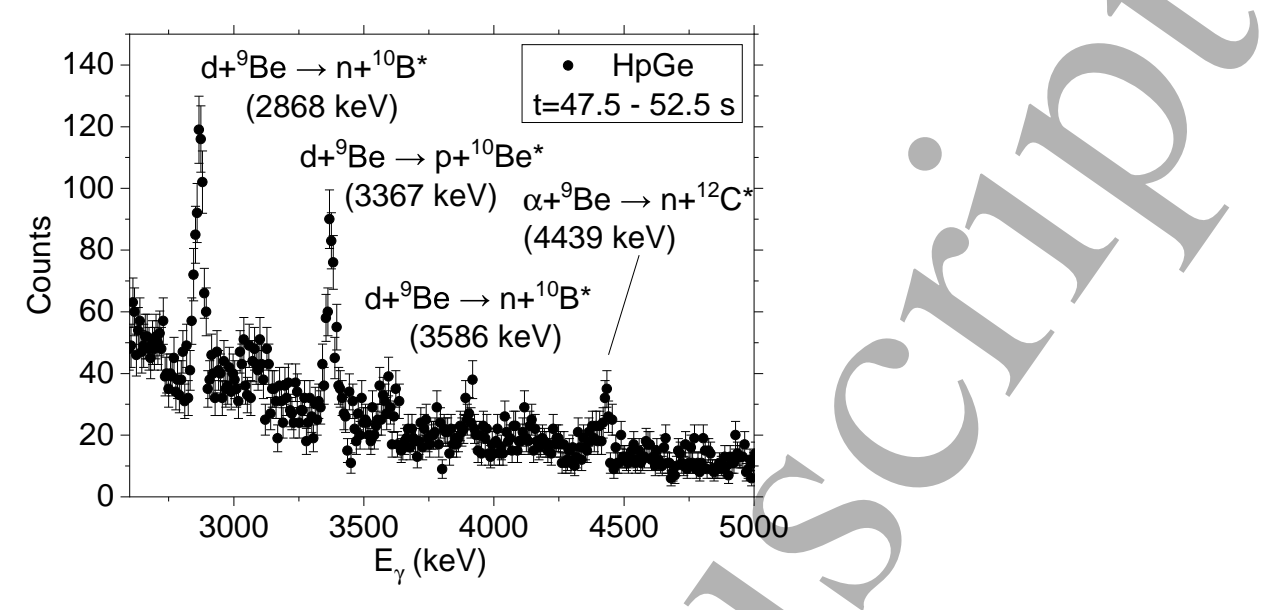

(a)

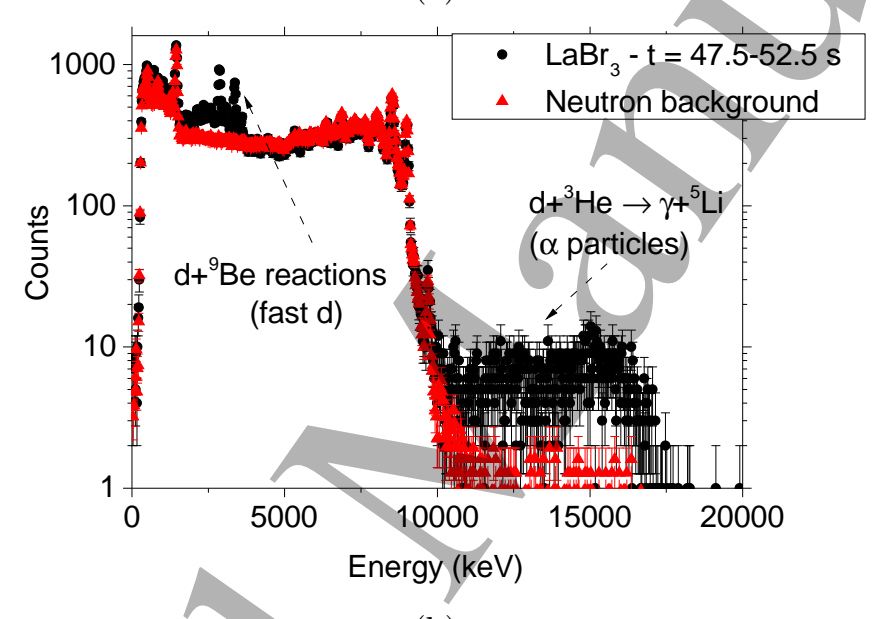

(b)

Figure 3. Gamma-ray spectra measured in JET pulse \#95679. (a) Data obtained with the high-purity Germanium detector with a vertical line-of-sight passing through the plasma core. The most prominent gamma-ray lines are labelled by the reaction they come from. (b) Data from the $\mathrm{LaBr}_{3}(\mathrm{Ce})$ detector with a horizontal line-of-sight that passes about $30 \mathrm{~cm}$ below the magnetic axis. The broad structure in the energy range $\mathrm{E}_{\gamma}>10 \mathrm{MeV}$ comes from a weak branch of the $\mathrm{D}-{ }^{3} \mathrm{He}$ fusion reaction with ${ }^{5} \mathrm{Li}$ as the fusion product. For $\mathrm{E}_{\gamma}<5 \mathrm{MeV}$ the same peaks of figure (a) are measured by this detector as well.

neutron camera data for pulse \#95679, highlighting that neutrons are mostly born in a small zone of $\approx 20 \mathrm{~cm}$ around the magnetic axis. This result confirms the theoretical expectations for the 3-ion ICRF scenario that energetic D ions are effectively generated in the vicinity of the IIH layer in the core of $\mathrm{D}-{ }^{3}$ He plasmas, see Fig. 1. The large population of fast ions, deuterons and fusion-born alpha particles, is accompanied by a rich variety of Alfvénic eigenmodes (AEs). Figure 4 shows the MHD spectrograms measured by the magnetic coils in pulses \#94698 and \#95679, including toroidicity- (TAEs) and ellipticity-induced (EAEs), reversed shear (RSAEs) and global $n=0$ AEs (GAEs; for simplicity, these are still marked as EAEs in the figure as they appear in that frequency range) [27]. An assessment of the nature of these MHD modes 
Fast ion generation with the $\mathrm{D}-{ }^{3} \mathrm{He}$ 3-ion scenario
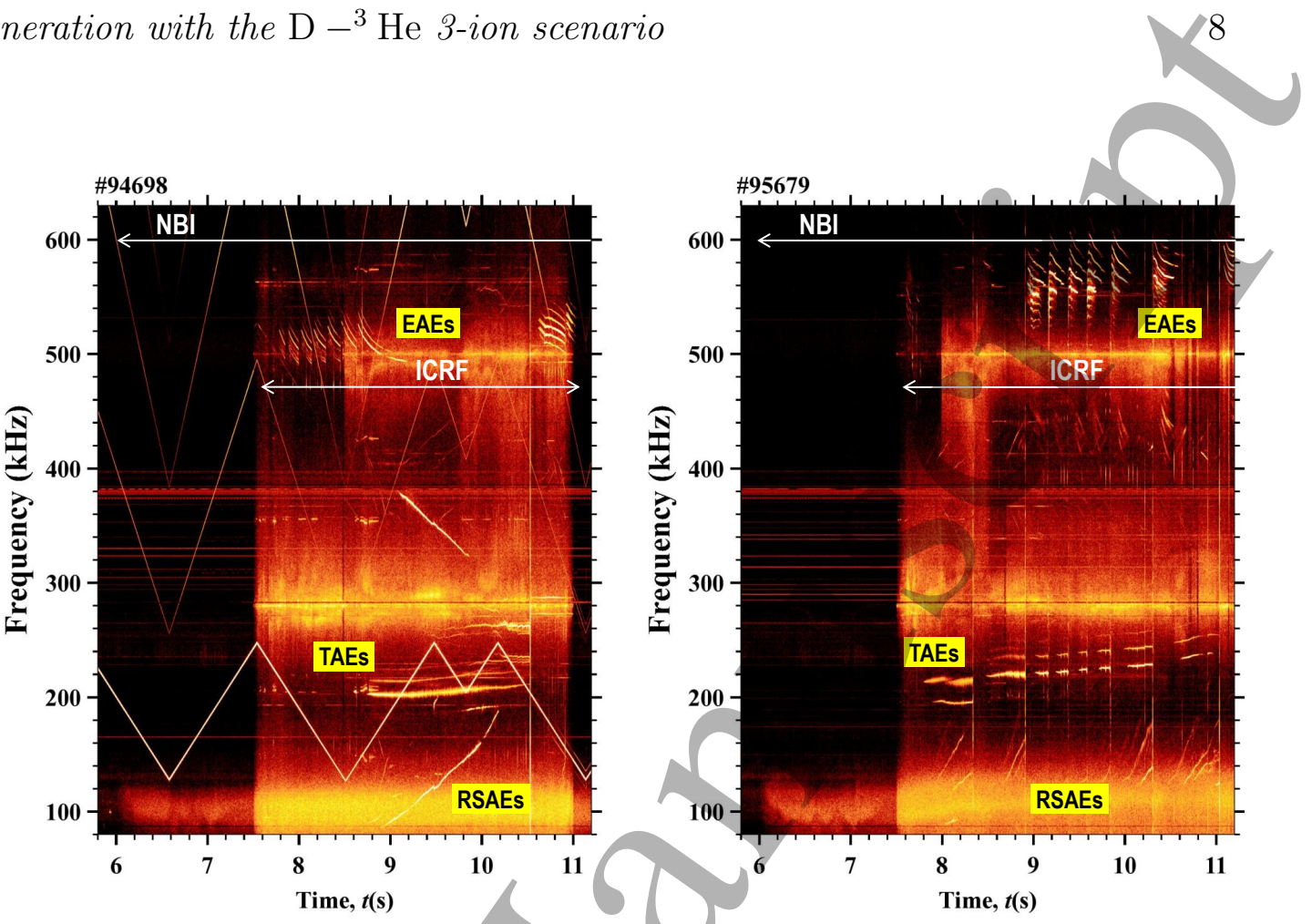

Figure 4. A rich variety of fast-on driven Alfvén eigenmodes is observed in $\mathrm{D}-{ }^{3}$ He plasmas using the 3 -ion D $-\left(\mathrm{D}_{\mathrm{NBI}}\right)-{ }^{3}$ He scenario: (left) \#94698 and (right) \#95679.

identifies those in the frequency range between $500 \mathrm{kHz}$ and $600 \mathrm{kHz}$ as EAEs and GAEs, while modes in the range $200 \mathrm{kHz}$ to $300 \mathrm{kHz}$ are identified as TAEs. RSAEs start at a frequency of about $100 \mathrm{kHz}$ and sweep up to the TAE frequencies, unless a sawtooth crash interrupts this evolution. All of these different AEs were regularly observed in this series of discharges in $\mathrm{D}-{ }^{3}$ He plasmas, suggesting that they must be related to the particular experimental conditions created by the use of the 3-ion scenario.

Furthermore, the presence of a specific type of AE instability depends on the duration of the sawtooth period. The discharges can be grouped in two categories, those with sawtooth periods of some hundreds of ms and those with periods of some seconds. The MHD spectrogram for the first type of discharges (see Fig. 4(b)) shows that EAEs and GAEs are particularly strong in this case, while RSAEs are short lived. Vice versa, during long-period sawteeth the RSAE frequency fully evolves until it approaches that of the TAE gap, see Fig. 4(a). By using the set of Mirnov coils available at JET we can further determine the toroidal number $\mathrm{n}$ of the observed modes. Besides instabilities with $\mathrm{n}=1$ through $\mathrm{n}=4$, both in the TAE and EAE frequency range, we also systematically observe modes with $\mathrm{n}=0$ (identified as a GAE) and EAEs with negative mode numbers, in particular $\mathrm{n}=-1$. The spatial localization of the AEs is 
provided by the correlation reflectometer, available for most of the discharges, indicating that the AEs are typically located close to the plasma core, within $\approx 20 \mathrm{~cm}$ from the magnetic axis.

For discharges with long sawtooth periods, the AE dynamics are more complex. As for cases with short sawteeth, EAEs appear about $90 \mathrm{~ms}$ after the crash and persist for about $100 \mathrm{~ms}$. An important observation in these discharges is the presence of RSAEs with $\mathrm{n}=3, \mathrm{n}=2$ and $\mathrm{n}=1$, with frequencies evolving in time from the Geodesic Acoustic Mode (GAM) up to the TAE frequencies. Interestingly, a continuous increase in neutron rate and plasma stored energy is regularly observed during the monster sawtooth phases with RSAEs. The very observation of RSAEs implies that the q-profile must be nonmonotonic in this phase. Since non-inductive current drive was not purposely applied by external means, an intrinsic mechanism must be present that drives the current necessary for the reversal in the q-profile. As discussed in the next section, the strong core localization of the RF power deposition characteristic of the 3 -ion ICRF scenarios leads to a very effective generation of a large population of fast co-passing $\mathrm{D}$ ions in the central region of the plasma. These fast D-ions are the obvious candidate particles to drive non-inductive current, which could contribute to the modification of the q-profile [6].

Despite the rich variety of MHD activities driven by the energetic ions, we find that these modes do not have a detrimental effect on the global plasma parameters. On the contrary, the energy confinement time and the ion and electron temperature profiles of these plasmas suggest that there is an overall beneficial effect of the fast particles on thermal plasma transport. Figure 5 shows the electron and ion temperature profiles measured in JET pulse \#94700 $\left(\mathrm{P}_{\mathrm{ICRF}} \approx 6.0 \mathrm{MW}\right.$ and $\left.\mathrm{P}_{\mathrm{NBI}} \approx 6.3 \mathrm{MW}\right)$, that illustrates the type of $\mathrm{T}_{\mathrm{e}}$ and $\mathrm{T}_{\mathrm{i}}$ profiles observed in this series of discharges. The ion temperature profile was obtained by charge exchange analysis of lines from Neon, which was purposely injected into the plasma for $\mathrm{T}_{\mathrm{i}}$ measurements. As the developed fast-ion scenario efficiently generates $\mathrm{MeV}$-range energetic ions, collisional electron heating is a dominant heating source in the plasma core, i.e. for a normalized toroidal radius $\rho<0.2$ according to TRANSP [28] simulations. In particular, TRANSP predicts that the electron heating is twice as large as ion heating at the location of the magnetic axis. Despite that, we systematically observe $\mathrm{T}_{\mathrm{i}} \approx \mathrm{T}_{\mathrm{e}}$ for all the pulses where good-quality Ne charge-exchange data are available. The observation that $\mathrm{T}_{\mathrm{i}} / \mathrm{T}_{\mathrm{e}} \approx 1$ in plasmas with dominant fastion electron heating is very promising in view of ITER. Despite the L-mode nature of the plasmas, a rather high plasma stored energy was systematically observed in the phases with the combined ICRF and NBI heating, compared to NBI only. A prominent example comes from the direct comparison between discharges \#94701 and \#94704, where the same total heating power of $14 \mathrm{MW}$ was applied by combined NBI+ICRF (\#94701) or NBI only (\#94704) (see figure 12 of [5]). The plasma stored energy is twice as large for \#94701 compared to \#94704. This observation, in combination with the direct comparison of $\mathrm{T}_{\mathrm{e}}$ and $\mathrm{T}_{\mathrm{i}}$ profiles for $\mathrm{D}-{ }^{3}$ He plasmas heated with NBI-only at the same total heating power, plasma density and other operational conditions (see 


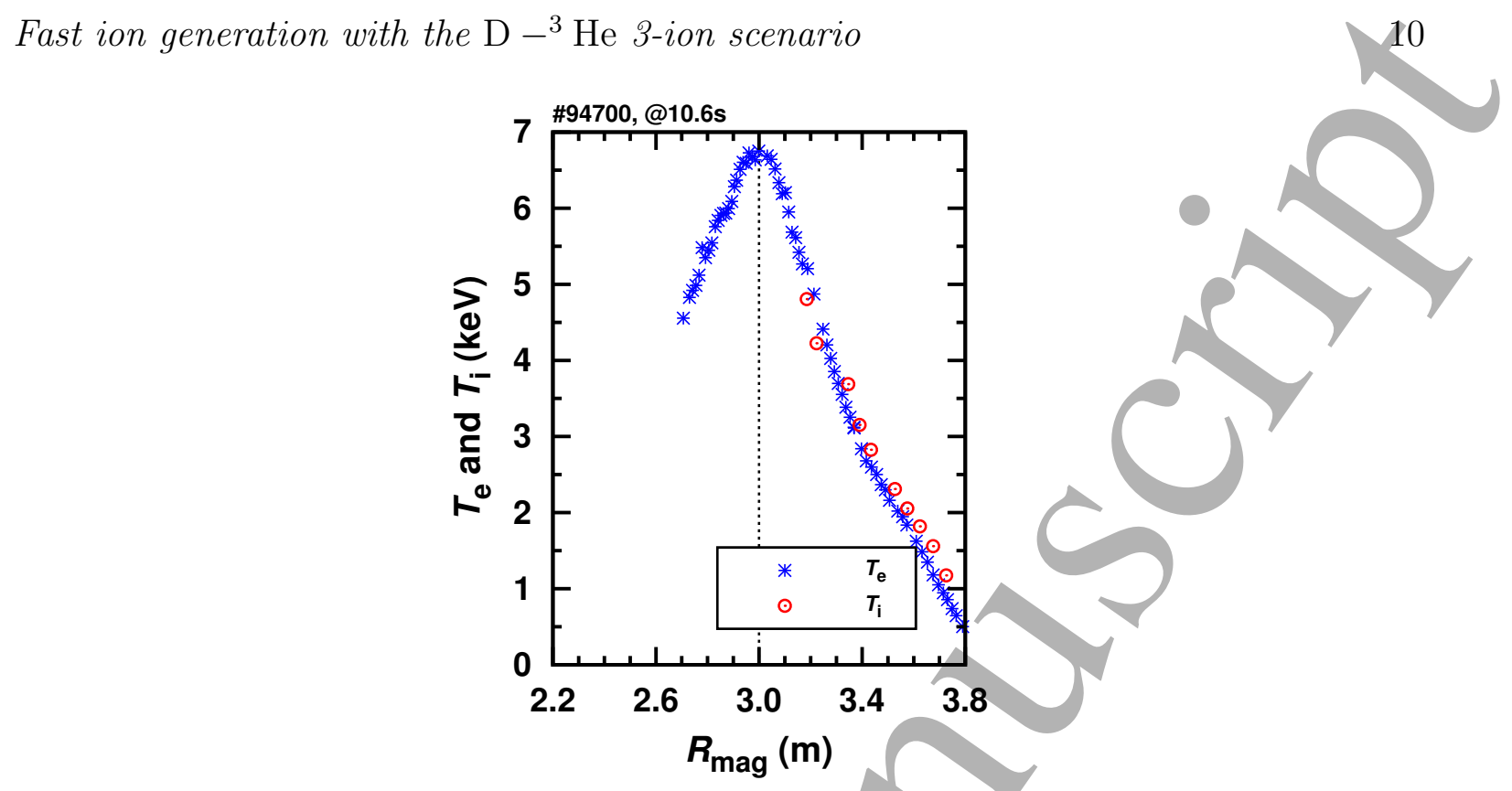

Figure 5. Illustration of the electron and ion temperature profiles in JET experiments in $\mathrm{D}-{ }^{3}$ He plasmas, in which the 3 -ion $\mathrm{D}-\left(\mathrm{D}_{\mathrm{NBI}}\right)-{ }^{3} \mathrm{He}$ ICRF scenario accelerated $\mathrm{D}-\mathrm{NBI}$ ions to $\mathrm{MeV}$ range energies. The example shows $\mathrm{T}_{\mathrm{e}}$ and $\mathrm{T}_{\mathrm{i}}$ profiles measured in pulse $\# 94700$ at $\mathrm{t}=10.6 \mathrm{~s}\left(\mathrm{P}_{\mathrm{ICRF}} \approx 6.0 \mathrm{MW}, \mathrm{P}_{\mathrm{NBI}} \approx 6.3 \mathrm{MW}, \mathrm{n}_{\mathrm{e} 0} \approx 6 \times 10^{19} \mathrm{~m}^{-3}\right)$

Fig. 12 in [5]), implies that turbulent transport may have been reduced when the 3-ion $\mathrm{D}-\left(\mathrm{D}_{\mathrm{NBI}}\right)-{ }^{3} \mathrm{He}$ was applied for plasma heating.

The rich and partly unexpected variety of phenomena that are present in the discharges we have studied raise a number of questions that require a detailed further investigation. In what follows, we provide first hypotheses to explain the observations. A further detailed assessment is ongoing and will be reported in future papers.

\section{Discussion}

We first focus on the nature of the orbits of the fast deuterons generated with ICRF. As follows from quasi-linear theory [29, 30, 31], the evolution of the fast-ion distribution function $f_{0}$ under ICRF is described by

$$
<Q\left(f_{0}\right)>=\sum_{N, n, \omega} L_{N, n, \omega}\left(D_{0} L_{N, n, \omega} f_{0}\right)
$$

where $D_{0}$ is a diffusion coefficient and the operator $L_{n, N, \omega}$ is given by

$$
L_{n, N, \omega}=\omega \frac{\partial}{\partial E}+\frac{\omega_{c 0} n-\Lambda \omega}{E} \frac{\partial}{\partial \Lambda}+N \frac{\partial}{\partial P_{\Phi}}
$$

Here, $\omega$ is the angular RF frequency, $n$ is the cyclotron harmonic ( $n=1$ for the 3ion ICRF scenarios), $\omega_{c 0}$ is the on-axis cyclotron resonance frequency, $N$ is the toroidal mode number and $\phi$ is the toroidal angle. In this formalism, the phase space trajectories of resonant ions are described by changes of the energy $E$, normalized magnetic moment $\Lambda \Lambda=\mu B_{0} / E$, with $\mu$ the magnetic moment and $B_{0}$ the magnetic field at the magnetic 
axis) and toroidal component of the canonical angular momentum $P_{\phi}$. For a toroidally symmetric system $\frac{\partial}{\partial P_{\phi}}=0$. When collisions are neglected, we find from Eqs. 2 and 3 that small changes in $E$ and $\Lambda$ during ICRF acceleration are given by (see also Equation (22) in [29])

$$
\Delta \Lambda=\left(\Lambda_{\infty}-\Lambda\right) \frac{\Delta E}{E}
$$

where $\Lambda_{\infty}=\omega_{c 0} / \omega$. We note that $\Lambda_{\infty}$ acts as a phase space attractor, i.e. it is the asymptotic normalized magnetic moment that is approached by the particle as its energy increases under the application of ICRF. Equation 4 implies a detailed relationship between the particle pitch $\lambda=v_{\|} / v$ and its energy $E$. By noting that $\lambda^{2}=1-\Lambda^{2}$, one can show that

$$
\lambda(E)=\sqrt{\lambda_{\infty}^{2}+\frac{E_{0}}{E}\left(\lambda_{0}^{2}-\lambda_{\infty}^{2}\right)}
$$

which mathematically implies that $\lambda \rightarrow \lambda_{\infty}$ as $E \rightarrow \infty$, and where $\lambda_{0}$ is the pitch of the fast particle at the beginning of the acceleration.

For the 3-ion D $-\left(\mathrm{D}_{\mathrm{NBI}}\right)-{ }^{3} \mathrm{He}$ scenario with the IIH layer located on-axis $\left(B_{0}=3.7 \mathrm{~T}\right.$, $\mathrm{f}=32.2-33 \mathrm{MHz}), \lambda_{\infty} \approx 0.34-0.38$. Furthermore, the trapped-passing boundary in the plasma region very close to the magnetic axis has a peculiar structure that facilitates the presence of co-passing fast ions with $v_{\|}>0$ at energies above NBI injection energy. In this way, the combination of the strong localization of the RF power deposition in the plasma core, the non-standard trapped/passing boundary in that region and the quasilinear evolution of the fast ions ensure that co-passing NBI ions stay on passing orbits and do not become trapped as they absorb RF power and increase their energy [6]. We note that this is possible only thanks to the peculiar properties of the 3 -ion ICRF scenario, with very strong energy deposition and fast-ion generation in a small volume close to the magnetic axis (see also Figure 1). This is quite different from more common ICRF heating scenarios, e.g. minority ICRF heating, where the power absorption takes place in a larger (vertically stretched) plasma volume and at larger normalized radii $\rho$, such that ICRF-generated fast ions become predominantly trapped as they absorb RF power.

The result given by Eq. 5 is supported by TRANSP simulations for JET pulse \#95679. Figure 6(a) shows the computed distribution function of the fast $\mathrm{D}$ ions in the core region of the plasma as a function of their pitch at $E_{D}=0.8 \mathrm{MeV}, 1.1 \mathrm{MeV}$ and $1.4 \mathrm{MeV}$. At the NBI injection energy, the population of fast $\mathrm{D}$ ions is peaked at $\lambda_{0} \approx$ 0.62. As follows from Fig. 6(a), at high energies most of the ICRF-accelerated D-NBI ions have a pitch between 0.35 and 0.40 . Note that the perpendicular energy of these fast ions represents $\approx 85 \%$ of the total energy, consistent with the fact that RF cyclotron interaction predominantly increases the perpendicular velocity of resonant ions.

A direct confirmation of the co-passing nature of the fast deuterons comes from a detailed analysis of the shape of the $2.87 \mathrm{MeV}$ gamma-ray peak born from $\mathrm{D}+{ }^{9} \mathrm{Be}$ nuclear reactions and measured with a high purity Germanium (HpGe) detector. In Fig. 6(b) we show the sum of the experimental data from discharges \#95677, \#95679, 
Fast ion generation with the $\mathrm{D}-{ }^{3} \mathrm{He}$ 3-ion scenario

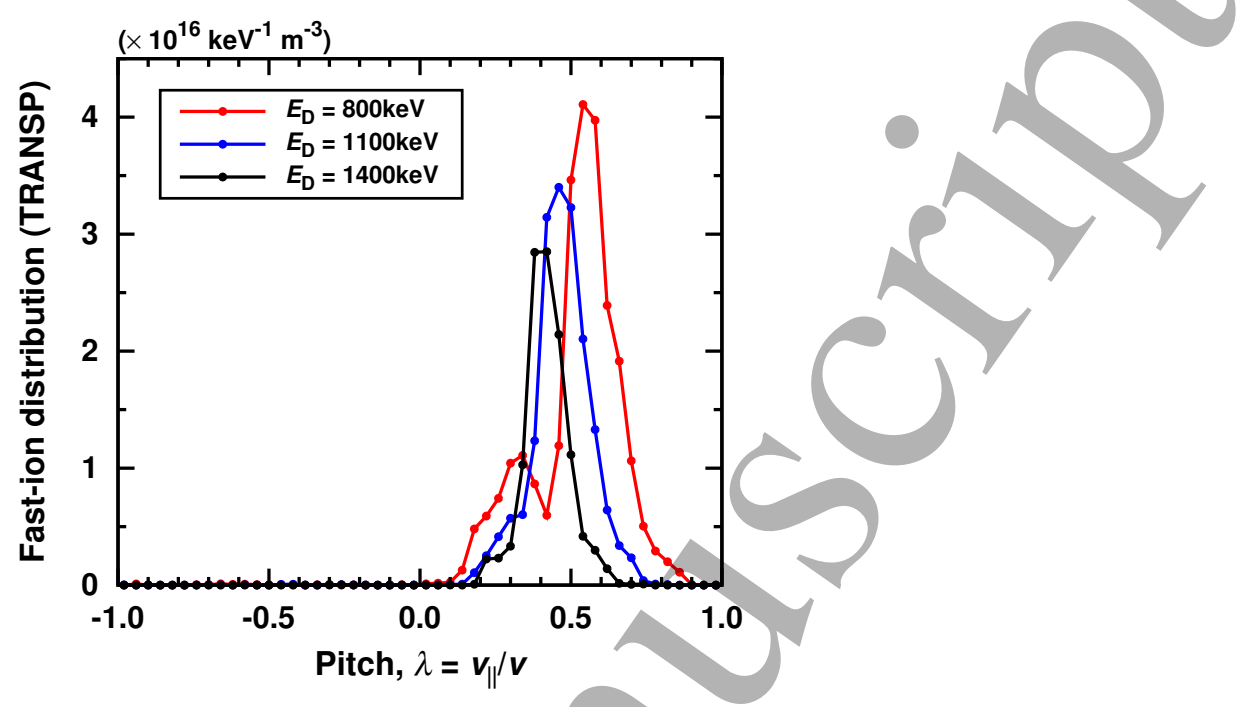

Figure 6. (a) The distribution function of ICRF-accelerated fast D ions in \#95679 at $E_{D}=800 \mathrm{keV}, 1100 \mathrm{keV}$ and $1400 \mathrm{keV}$ as a function of the pitch parameter, computed by the TRANSP code. (b) The measured shape of the $\mathrm{E}_{\gamma}=2.87 \mathrm{MeV}$ gamma-ray peak, originating from the reactions between fast $\mathrm{D}$ and ${ }^{9} \mathrm{Be}$, obtained by adding data from discharges \#95677, \#95679, \#95680 and \#95683. The solid and dashed lines show the calculated line shape, assuming the same energy distribution of the fast deuterons but for two different values of the pitch: $\lambda \approx 0$ (blue, dashed) and $\lambda \approx 0.4$ (red, solid).

\#95680, \#95683 where the HpGe was active, together with the expected shape of this line computed with the GENESIS code [20,32] and assuming that the fast deuterons have $\lambda \approx 0.4$ (solid red line) and $\lambda \approx 0.0$ (blue dotted line). The latter occurs in most of the commonly used ICRF scenarios. Besides the peak shape, with the code we can also compute the relative amount of gamma rays emitted in both cases. In this way, there is only one parameter to fit between simulations and data, i.e. the conversion factor between the output of the code for the $\lambda \approx 0.40$ case (gammas $/$ second $/ \mathrm{keV}$ produced along the instrument line of sight) and the counts measured experimentally in the region 
of the $2.87 \mathrm{MeV}$ peak. In agreement with theory, we find that the shape of the computed curves assuming $\lambda \approx 0.4$ agrees rather well with the measured shape of the $\mathrm{E}_{\gamma}=2.87$ $\mathrm{MeV}$ peak. For $\lambda \approx 0.0$, instead, the model systematically predicts lower values at the centre of the line. This synthetic analysis confirms that the 3 -ion ICRF scenario is effective in generating a large population of co-passing fast $\mathrm{D}$ ions with $\lambda \approx 0.3-0.5$ in the central region of the plasma.

We note that the co-passing deuterons may provide a current contribution that favours the excitation of the RSAEs. As noted earlier, the very observation of RSAEs (which appear in between the sawtooth crashes) implies that the q-profile must be nonmonotonic and one candidate contribution to the reversal of q may come from the copassing deuteron population itself, which could be slightly off-axis due to the Shafranov shift or the spatial redistribution resulting from its interaction with the MHD activity. While we are aware that the detailed relation between the presence of a co-passing deuteron population, the reversal of $\mathrm{q}$ and the excitation of RSAEs might be complex and therefore needs to be studied in detail, we also suggest that, if fully understood, it may transform the 3-ion ICRF scenario in a tool for tailoring the q profile in future applications. The topic will be the subject of future studies.

In addition to RSAEs, the fast ions excited various AE instabilities, particularly in the range between $500 \mathrm{kHz}$ and $600 \mathrm{kHz}$ with toroidal mode numbers $\mathrm{n}=0$ and $\mathrm{n}=-1$. As the appearance of these modes occurs together with the generation of an unusually large alpha particle population, at the level of $\approx 10^{16}$ particle/s according to TRANSP and thus comparable to the neutron emission from these plasmas as measured by the fission chambers (see figure 2), a possibility exists that some of the modes may be partly or entirely alpha driven. This applies in particular to the above mentioned $n=0$ and $n=-1$ instabilities, whose resonance conditions seem to be more easily satisfied by the $\mathrm{MeV}$ range, relatively isotropic alpha particle population according to an ongoing analysis [33].

The rich variety of AE activities present in the plasma does not have a detrimental effect on the global plasma parameters but, on the contrary, comparable electron and ion temperature are observed in all our discharges with dominant fast-ion electron heating in the plasma core, as surmised for burning plasmas in ITER. Since this is accompanied by a factor 2 higher plasma stored energy compared with plasmas with same input heating power delivered by NBI only, we suggest that the presence of the large population of fast ions located in a small volume around the plasma core may play some key role in improving the energy confinement. A similar observation was made earlier in connection with experiments at ASDEX Upgrade and JET both in L-mode [34] and Hmode $[35,36]$ with different sources of fast ions such as ${ }^{3} \mathrm{He}$ ions generated with ICRF minority heating or NBI fast ions. An explanation of the turbulence mitigation observed in those experiments was advanced in a number of papers, where a key contribution of the energetic ions to the mitigation of Ion Temperature Gradient modes by different mechanisms was found through gyrokinetic simulations [37, 38, 39, 40, 41]. Although the ICRF heating scheme adopted in our scenario is different with respect to that used 
in the former experiments, i.e. 3 ion versus ${ }^{3} \mathrm{He}$ minority ICRF, we share with the latter the presence of a significant, core localized population of fast ions in the MeV range, as well as the experimental observation of a larger than expected bulk ion temperature. For these reasons, we surmise that our scenario may be of interest also for studies on the effects that a large fast ion population in the $\mathrm{MeV}$ range can have on the mitigation of bulk plasma turbulence, in view of understanding the role that DT fusion born $\alpha$ particles may have in this respect [42].

\section{Conclusions}

Dedicated experiments to generate alpha particles from the $\mathrm{D}-{ }^{3} \mathrm{He}$ fusion reaction were performed at JET. The experiments were conducted in $\mathrm{D}-{ }^{3}$ He plasmas with the 3-ion $\mathrm{D}-\left(\mathrm{D}_{\mathrm{NBI}}\right)-{ }^{3} \mathrm{He}$ ICRF scenario, in which deuterium ions from NBI are accelerated up to $\mathrm{MeV}$-range energies and ${ }^{3} \mathrm{He}$ acts as the target of the fusion reactions. The alpha particles (with a production rate in excess of $10^{16} \mathrm{~s}^{-1}$ ) and co-passing fast deuterons are generated in a narrow zone around the plasma center as experimentally demonstrated by gamma-ray and neutron measurements.

Most importantly, these plasmas show rather unique phenomena, such as a rich variety of AEs, in particular elliptical and reversed shear AEs, and ion and electron temperature profiles with very similar shape and central temperature values, despite the dominant fast-ion electron heating. We propose hypotheses that may explain our experimental findings such as, e.g., the possibility that fusion-born alpha particles contribute to drive some of the AEs, as well as effects from large populations of ICRF-generated co-passing deuterium ions on current drive and modifications of the q-profile. The results we have reported are highly relevant for the development of a scenario that maximizes the production of alpha particles and thus the observation of their effects on the plasma in forthcoming deuterium-tritium experiments at JET. The experimental conditions obtained in our discharges may therefore be of more general interest, as they seem to anticipate novel aspects of alpha particle physics in plasmas without tritium.

\section{Acknowledgments}

This work has been carried out within the framework of the EUROfusion Consortium and has received funding from the Euratom research and training programme 2014-2018 and 2019-2020 under grant agreement No 633053. The views and opinions expressed herein do not necessarily reflect those of the European Commission.

\section{References}

[1] Emmanuel Joffrin, Sadrilla Abduallev, Mitul Abhangi, P Abreu, V Afanasev, M Afzal, KM Aggarwal, T Ahlgren, L Aho-Mantila, N Aiba, et al. Overview of the jet preparation for deuterium-tritium operation with the iter like-wall. Nuclear Fusion, 59(11):112021, 2019. 
1

2

3

4

5

6

7

8

9

Fast ion generation with the $\mathrm{D}-{ }^{3} \mathrm{He}$ 3-ion scenario

[2] RJ Dumont, J Mailloux, V Aslanyan, M Baruzzo, CD Challis, I Coffey, A Czarnecka, E Delabie, Jacob Eriksson, J Faustin, et al. Scenario development for the observation of alpha-driven instabilities in jet dt plasmas. Nuclear Fusion, 58(8):082005, 2018.

[3] Ye O Kazakov, D Van Eester, R Dumont, and J Ongena. On resonant icrf absorption in three-ion component plasmas: a new promising tool for fast ion generation. Nuclear Fusion, 55(3):032001, 2015.

[4] Ye O Kazakov, J Ongena, JC Wright, SJ Wukitch, E Lerche, MJ Mantsinen, D Van Eester, T Craciunescu, VG Kiptily, Y Lin, et al. Efficient generation of energetie ions in multi-ion plasmas by radio-frequency heating. Nature Physics, 13(10):973-978, 2017.

[5] Yevgen Kazakov, Massimo Nocente, Mervi Mantsinen, Jozef Ongena, Yuriy Baranov, Teddy Craciunescu, Mykola Dreval, Remi Dumont, Jacob Eriksson, Jeronimo Garcia, et al. Plasma heating and generation of energetic $d$ ions with the 3-ion icrf + nbi scheme in mixed hd plasmas at jet-ilw. Nuclear Fusion, 60(11):112013, 2020.

[6] Ye.O. Kazakov et al. Physics and applications of the 3-ion icrf scenarios for fusion research. submitted to Physics of Plasmas.

[7] M Nocente, G Gorini, Jan Källne, and M Tardocchi. Cross section of the $d+3$ he $\rightarrow \alpha+p$ reaction of relevance for fusion plasma applications. Nuclear fusion, 50(5):055001, 2010.

[8] MJ Mantsinen, V Bobkov, D Gallart, A Kappatou, Ye O Kazakov, M Weiland, JET Contributors, ASDEX Upgrade Team, EUROfusion MST1 Team, et al. Modelling of three-ion icrf schemes with pion. In 46th EPS Conference on Plasma Physics. European Physical Society, 2019.

[9] Jacob Eriksson, Carl Hellesen, Federico Binda, Marco Cecconello, Sean Conroy, Göran Ericsson, L Giacomelli, G Gorini, Anders Hjalmarsson, VG Kiptily, et al. Measuring fast ions in fusion plasmas with neutron diagnostics at jet. Plasma Physics and Controlled Fusion, 61(1):014027, 2018.

[10] M Nocente, A Dal Molin, N Eidietis, L Giacomelli, G Gorini, Y Kazakov, E Khilkevitch, V Kiptily, M Iliasova, A Lvovskiy, et al. Mev range particle physics studies in tokamak plasmas using gamma-ray spectroscopy. Plasma Physics and Controlled Fusion, 62(1):014015, 2019.

[11] VG Kiptily, FE Cecil, and SS Medley. Gamma ray diagnostics of high temperature magnetically confined fusion plasmas. Plasma physics and controlled fusion, 48(8):R59, 2006.

[12] Dmitry Moseev, Mirko Salewski, M Garcia-Muñoz, B Geiger, and M Nocente. Recent progress in fast-ion diagnostics for magnetically confined plasmas. Reviews of Modern Plasma Physics, 2(1):7, 2018.

[13] Mirko Salewski, M Nocente, Asger Schou Jacobsen, Federico Binda, C Cazzaniga, Göran Ericsson, Jacob Eriksson, G Gorini, Carl Hellesen, Anders Hjalmarsson, et al. Mev-range velocity-space tomography from gamma-ray and neutron emission spectrometry measurements at jet. Nuclear Fusion, 57(5):056001, 2017.

[14] M Nocente, M Tardocchi, A Olariu, S Olariu, RC Pereira, IN Chugunov, A Fernandes, DB Gin, G Grosso, VG Kiptily, et al. High resolution gamma ray spectroscopy at mhz counting rates with labr $-\{3\}$ scintillators for fusion plasma applications. IEEE Transactions on Nuclear Science, $60(2): 1408-1415,2013$.

[15] M Nocente, D Rigamonti, V Perseo, M Tardocchi, G Boltruczyk, A Broslawski, A Cremona, G Croci, M Gosk, V Kiptily, et al. Gamma-ray spectroscopy at mhz counting rates with a compact labr3 detector and silicon photomultipliers for fusion plasma applications. Review of Scientific Instruments, 87(11):11E714, 2016.

[16] D Rigamonti, A Muraro, M Nocente, V Perseo, G Boltruczyk, A Fernandes, J Figueiredo, L Giacomelli, G Gorini, M Gosk, et al. Performance of the prototype labr3 spectrometer developed for the jet gamma-ray camera upgrade. Review of Scientific Instruments, 87(11):11E717, 2016.

[17] D Rigamonti, A Broslawski, A Fernandes, J Figueiredo, L Giacomelli, G Gorini, M Gosk, G Kaveney, V Kiptily, S Korolczuk, et al. The upgraded jet gamma-ray cameras based on high resolution/high count rate compact spectrometers. Review of Scientific Instruments, 
89(10):10I116, 2018.

[18] JM Adams, ON Jarvis, GJ Sadler, DB Syme, and N Watkins. The jet neutron emission profile monitor. Nuclear Instruments and Methods in Physics Research Section A: Accelerators, Spectrometers, Detectors and Associated Equipment, 329(1-2):277-290, 1993.

[19] M Gatu Johnson, L Giacomelli, Anders Hjalmarsson, Jan Källne, Matthias Weiszflog, E Andersson Sundén, Sean Conroy, Göran Ericsson, Carl Hellesen, Emanuele Ronchi, et al. The 2,5-mev neutron time-of-flight spectrometer tofor for experiments at jet. Nuclear Instruments and Methods in Physics Research Section A: Accelerators, Spectrometers, Detectors and Associated Equipment, 591(2):417-430, 2008.

[20] Marco Tardocchi, M Nocente, I Proverbio, VG Kiptily, P Blanchard, Sean Conroy, M Fontanesi, G Grosso, K Kneupner, E Lerche, et al. Spectral broadening of characteristic $\gamma$-ray emission peaks from c 12 (he 3, p $\gamma$ ) n 14 reactions in fusion plasmas. Physical review letters, 107(20):205002, 2011.

[21] M Nocente, M Tardocchi, I Chugunov, RC Pereira, T Edlington, AM Fernandes, D Gin, G Grosso, V Kiptily, A Murari, et al. Energy resolution of gamma-ray spectroscopy of jet plasmas with a labr 3 scintillator detector and digital data acquisition. Review of scientific instruments, 81(10):10D321, 2010.

[22] Jacob Eriksson, Massimo Nocente, Federico Binda, Carlo Cazzaniga, Sean Conroy, Göran Ericsson, L Giacomelli, G Gorini, C Hellesen, Torbjörn Hellsten, et al. Dual sightline measurements of mev range deuterons with neutron and gamma-ray spectroscopy at jet. Nuclear Fusion, 55(12):123026, 2015.

[23] VG Kiptily, FE Cecil, ON Jarvis, MJ Mantsinen, SE Sharapov, L Bertalot, S Conroy, LC Ingesson, $\mathrm{T}$ Johnson, KD Lawson, et al. $\gamma$-ray diagnosties of energetic ions in jet. Nuclear Fusion, 42(8):999, 2002.

[24] SE Sharapov, Torbjörn Hellsten, VG Kiptily, T Craciunescu, Jacob Eriksson, M Fitzgerald, J-B Girardo, V Goloborod'ko, Carl Hellesen, Anders Hjalmarsson, et al. Fusion product studies via fast ion d-d and d-3he fusion on jet. Nuclear Fusion, 56(11):112021, 2016.

[25] Massimo Nocente, Marco Tardocchi, Robin Barnsley, Luciano Bertalot, Benoit Brichard, Gabriele Croci, Giorgio Brolatti, L Di Pace, A Fernandes, Luca Giacomelli, et al. Conceptual design of the radial gamma ray spectrometers system for $\alpha$ particle and runaway electron measurements at iter. Nuclear Fusion, 57(7):076016, 2017.

[26] M Nocente, Jan Källne, Mirko Salewski, M Tardocchi, and G Gorini. Gamma-ray emission spectrum from thermonuclear fusion reactions without intrinsic broadening. Nuclear Fusion, $55(12): 123009,2015$.

[27] Nikolai N Gorelenkov, SD Pinches, and K Toi. Energetic particle physics in fusion research in preparation for burning plasma experiments. Nuclear Fusion, 54(12):125001, 2014.

[28] RV Budny. A standard dt supershot simulation. Nuclear Fusion, 34(9):1247, 1994.

[29] L-G Eriksson, MJ Mantsinen, T Hellsten, and J Carlsson. On the orbit-averaged monte carlo operator describing ion cyclotron resonance frequency wave-particle interaction in a tokamak. Physics of Plasmas, 6(2):513-518, 1999.

[30] Thomas Howard Stix. Fast-wave heating of a two-component plasma. Nuclear Fusion, 15(5):737, 1975.

[31] Allan N Kaufman. Quasilinear diffusion of an axisymmetric toroidal plasma. The Physics of Fluids, 15(6):1063-1069, 1972.

[32] Massimo Nocente. Neutron and gamma-ray emission spectroscopy as fast ion diagnostics in fusion plasmas. PhD thesis, University of Milano-Bicocca, 2012.

[33] V.G. Kiptily et al. Evidence for alfvén eigenmodes driven by alphaparticlesin d- ${ }^{3}$ he fusion experiments on jet. submitted to Phys. Rev. Letters.

[34] P Mantica, C Angioni, B Baiocchi, M Baruzzo, MNA Beurskens, JPS Bizarro, RV Budny, P Buratti, A Casati, C Challis, et al. Ion heat transport studies in jet. Plasma Physics and Controlled Fusion, 53(12):124033, 2011. 
1

2

3

4

5

6

7

8

9

Fast ion generation with the $\mathrm{D}-{ }^{3} \mathrm{He}$ 3-ion scenario

[35] Clive D Challis, J Garcia, M Beurskens, P Buratti, E Delabie, P Drewelow, Lorenzo Frassinetti, $\mathrm{C}$ Giroud, N Hawkes, J Hobirk, et al. Improved confinement in jet high $\beta$ plasmas with an iter-like wall. Nuclear Fusion, 55(5):053031, 2015.

[36] MJ Mantsinen, Roberto Bilato, VV Bobkov, Athina Kappatou, RM McDermott, Massimo Nocente, T Odstrčil, Giovanni Tardini, Matthias Bernert, Ralph Dux, et al. Bulk ion heating with icrf waves in tokamaks. In AIP Conference Proceedings, volume 1689, page 030005. AIP Publishing LLC, 2015.

[37] Jonathan Citrin, F Jenko, P Mantica, D Told, C Bourdelle, J Garcia, JW Haverkort, GMD Hogeweij, Thomas Johnson, and MJ Pueschel. Nonlinear stabilization of tokamak microturbulence by fast ions. Physical review letters, 111(15):155001, 2013.

[38] N Bonanomi, P Mantica, A Di Siena, E Delabie, C Giroud, Thomas Johnson, E Lerche, S Menmuir, M Tsalas, D Van Eester, et al. Turbulent transport stabilization by icrh minority fast ions in low rotating jet ilw l-mode plasmas. Nuclear Fusion, 58(5):056025, 2018.

[39] A Di Siena, T Görler, E Poli, A Bañón Navarro, A Biancalani, and F Jenko. Electromagnetic turbulence suppression by energetic particle driven modes. Nuclear Fusion, 59(12):124001, 2019.

[40] J Garcia, C Challis, J Citrin, H Doerk, G Giruzzi, T Görler, F Jenko, P Maget, and JET Contributors. Key impact of finite-beta and fast ions in core and edge tokamak regions for the transition to advanced scenarios. Nuclear Fusion, 55(5):053007, 2015.

[41] H Doerk, C Challis, J Citrin, J Garcia, T Görler, F Jenko, and JET Contributors. Gyrokinetic study of turbulence suppression in a jet-ilw/power scan. Plasma Physics and Controlled Fusion, 58(11):115005, 2016.

[42] J Garcia, $\mathrm{T}$ Görler, and $\mathrm{F}$ Jenko. Isotope and fast ions turbulence suppression effects: Consequences for high- $\beta$ iter plasmas. Physics of Plasmas, 25(5):055902, 2018. 